\title{
Lick rates in infant Mongolian gerbils
}

\author{
ROBERT T. DICKINSON and ROBERT W. SCHAEFFER \\ Auburn University, Auburn, Alabama 96830
}

\begin{abstract}
Licking rates as a function of age were assessed in six female and one male infant Mongolian gerbils (Meriones unguiculatus) over a 20-day period. The data supported previous research by showing that infant and adult gerbil lick rates differ. The magnitude of these differences was small, and did not contradict the lick rate invariance hypothesis. In contrast to previous data, however, lick rate variability was relatively constant over time.
\end{abstract}

Since Stellar and Hill (1952) observed that rats drink at a constant rate of six to seven licks/sec, numerous investigators have provided experimental support for this "invariance hypothesis," noting that lick rates are apparently constant regardless of age (Schaeffer \& Premack, 1961), sex (Schaeffer \& Huff, 1965), fluid deprivation level (Corbit \& Luschei, 1969), or type of fluid ingested (Hulse \& Suter, 1968). However, recent research with the Mongolian gerbil (Meriones unguiculatus) has suggested that infant and adult lick rates differ within this species. Schaeffer and David (1973) found the lick rates of 26-day-old gerbils to be slower and more restricted in range than those of adult gerbils. Subsequently, Pierson and Schaeffer (1975), investigating the development of lick rates in infant Mongolian gerbils in a longitudinal study, reported that infant gerbil lick rates were both faster and slower than adult lick rates before the age of 35 days. After this age, the lick rates of infant and adult gerbils were virtually identical. These investigators also found that lick rate variability diminished after age 35 days. The present experiment was undertaken as a systematic replication of the findings of Pierson and Schaeffer (1975) and was intended to identify more accurately the period at which infant lick rates develop the characteristics of adult lick rates.

\section{METHOD}

\section{Subjects}

One male and six female experimentally naive Mongolian gerbils (Meriones unguiculatus) served as subjects. All animals were 31 days old at the start of testing and, prior to that time, had received all fluids via nursing. The gerbils were maintained on Purina pelleted Lab Chow during the experiment.

\section{Apparatus and Procedure}

Each gerbil was individually housed in a clear plastic lab cage measuring $18.0 \mathrm{~cm}$ wide, $29.0 \mathrm{~cm}$ long, and $12.5 \mathrm{~cm}$ high, with approximately $.5 \mathrm{~cm}$ of San-i-cel used as bedding material. Four plastic cages, identical to the home cages, were used as experimental chambers. The test cages were modified by placing a hardware cloth cover, with a bottle holder of the same material mounted at one end, over the cage. A plastic water bottle with a Wahmann stainless steel drinking tube was inverted in the bottle holder to allow the tube to extend approximately $2 \mathrm{~cm}$ into the cage. The tube was coated with Formvar, a Dupont insulating material, to insure that tongue-fluid contacts were not contaminated by nose-tube or body-tube contacts. The tube orifice, $1 \mathrm{~mm}$ in diam, was positioned approximately $8 \mathrm{~cm}$ above a $5.5 \times 11.5 \mathrm{~cm}$ metal drinking platform. The drinking platform was elevated $3.0 \mathrm{~cm}$ above the cage floor. The platform and drinking tube comprised the two sides of a drinkometer circuit. Tongue-fluid contacts activated a transistorized relay circuit capable of sensing 50 impulses/sec. The relay circuitry in turn activated the recording pens of an Esterline-Angus digital-operations event recorder (Model AW). With the chart paper moving at a speed of $1.905 \mathrm{~cm} / \mathrm{sec}$, a permanent record was made of each lick.

All animals were weaned when 29 days old. After a 48-h period of water deprivation, the first drinking and testing session began. Each subject was placed in one of the four test chambers for a 30-min period, during which all tonguefluid contacts were recorded. Each animal was water deprived for $23.5 \mathrm{~h}$ prior to all test sessions, being allowed to drink only during the 30 -min test period. The experiment was terminated when all subjects demonstrated mean momentary lick rates equal to or faster than adult gerbil lick rates (cf. Schaeffer \& David, 1973) over a 10-day period. Recorded licks were analyzed using the procedures described by Schaeffer and Huff (1965) to determine (a) momentary lick rates, using a second-by-second analysis of all licks, (b) mean lick rates for bursts longer than $5 \mathrm{sec}$ in duration, and (c) duration of lick bursts.

\section{RESULTS AND DISCUSSION}

From the second-by-second analysis of all recorded licks, mean and modal momentary lick rates for 5-day intervals were obtained for each animal. These results, as well as the ranges of momentary lick rates, are summarized in Table 1 . The results demonstrated a general trend for mean momentary lick rates to increase slowly as a function of age. The mean of the momentary lick rates for all animals increased from 6.2 licks/sec at age 31-35 days to an overall average of 7.0 licks/sec at age 46-50 days. The 5-day modal momentary lick rates varied from six to seven licks/sec across subjects from 31-35 days of age but stabilized at seven licks/sec for the three 5-day intervals from 36-50 days of age. From age 42 days onward, all seven animals showed daily modal lick rates of seven licks/sec.

The rate of licking in bursts of $5 \mathrm{sec}$ or more duration paralleled the mean momentary rates, as most licks 
Table 1

Mean and Modal Momentary Lick Rates and Ranges of Male (M) and Female (F) Gerbils

\begin{tabular}{|c|c|c|c|c|c|c|c|c|c|c|c|c|}
\hline \multirow[b]{2}{*}{ Subjects } & \multicolumn{3}{|c|}{ 31-35 Days of Age } & \multicolumn{3}{|c|}{ 36-40 Days of Age } & \multicolumn{3}{|c|}{ 41-45 Days of Age } & \multicolumn{3}{|c|}{ 46-50 Days of Age } \\
\hline & Mean & Mode & Range & Mean & Mode & Range & Mean & Mode & Range & Mean & Mode & Range \\
\hline S1 (F) & 6.4 & 7 & $4-8$ & 7.2 & 7 & $3-15$ & 6.8 & 7 & $3-11$ & 7.1 & 7 & $4-9$ \\
\hline S2 (F) & 6.3 & 6 & $3-10$ & 6.7 & 7 & $4-12$ & 6.7 & 7 & $3-13$ & 7.1 & 7 & $4-13$ \\
\hline S3 (F) & 6.3 & 7 & 4-8 & 6.8 & 7 & $3-13$ & 7.2 & 7 & $3-14$ & 7.0 & 7 & $4-10$ \\
\hline S4 (M) & 6.0 & 6 & $3-8$ & 6.3 & 7 & $3-9$ & 6.6 & 7 & $3-15$ & 6.9 & 7 & $4-10$ \\
\hline S5 (F) & 5.9 & 6 & $4-11$ & 6.4 & 7 & $4-9$ & 7.0 & 7 & $5-8$ & 7.2 & 7 & $5-9$ \\
\hline S6 (F) & 6.3 & 6 & $4-9$ & 6.5 & 7 & $4-11$ & 6.8 & 7 & $5-9$ & 7.0 & 7 & $5-9$ \\
\hline S7 (F) & 6.4 & 6 & $4-11$ & 6.6 & 7 & $4-9$ & 7.0 & 7 & $5-8$ & 7.0 & 7 & $5-9$ \\
\hline
\end{tabular}

emitted fell into bursts. The temporal duration of the bursts varied from the lower limit of $5 \mathrm{sec}$ of continuous licking to a maximum of $288 \mathrm{sec}$ of continuous licking. Continuous licking was defined as a series of licks with no interlick interval greater than $.5 \mathrm{sec}$. The majority of lick bursts for each animal was less than $30 \mathrm{sec}$ in duration. Averaged across all animals, approximately $19 \%$ of all bursts exceeded $60 \mathrm{sec}$ in duration. The data also revealed that the relative frequency of longer bursts rose with increasing age, with most of the very long lick bursts appearing in the 41- to 50-days-of-age recordings.

The lick rate ranges, though declining over time for three subjects (S5, S6, S7), showed no overall declining trend for the other four subjects. Thus, variability of momentary lick rates, as assessed by range data, remained relatively stable over time. All gerbils appeared capable of producing both fast (i.e., 9-11 licks/sec) and slow (i.e., 3-5 licks/sec) rates of licking throughout the experiment.

The present study confirmed the general findings of the other investigators (Pierson \& Schaeffer, 1975; Schaeffer \& David, 1973) that mean momentary lick rates in gerbils change as a function of age. However, the change noted in the present study was approximately one lick/sec and does not, therefore, appear to contradict the implications of the invariance hypothesis. The search for a specific day or period of time when lick rates changed from infant to adult rates proved unfruitful. Instead, a relatively smooth transition over the 20 days of testing was noted. The finding that modal rates for each animal stabilized at seven licks/sec after age 41 days suggests that the period from age $34-41$ days may be the critical time for the first appearance of adult patterns of licking.
The mean momentary lick rates of approximately 7.0 licks/sec observed in all subjects from age 46-50 days are somewhat higher than those reported by Pierson and Schaeffer (1975) and Schaeffer and David (1973). The maximum difference noted was only of the order of one lick/sec, however, and could quite possibly be due to either animal strain differences or experimental methodology. The finding of little or no alteration in lick rate ranges as a function of age is not so easily explained. Factors such as apparatus differences or age of animals at time of testing may have played a role in these discrepant findings. Additional work now in progress hopefully will more precisely identify the specific factors responsible for these differences.

\section{REFERENCES}

Corbit, J. D., \& Luschei, E. S. Invariance of the rat's rate of drinking. Journal of Comparative and Physiological Psychology, 1969, 69, 119-125.

Hulse, S. H., \& Suter, S. One-drop licking in rats. Journal of Comparative and Physiological Psychology, 1968, 66, 536-539.

Pierson, S. C., \& Schaeffer, R. W. Lick rate development in infant Mongolian gerbils. Bulletin of the Psychonomic Society, 1975, 5, 47-48.

SchaEfFer, R. W., \& David, M. Lick rates in gerbils. Bulletin of the Psychonomic Society, 1973, 2, 257-260.

Schaeffer, R. W., \& HufF, R. Lick rates in cats. Psychonomic Science, 1965, 3, 377-378.

Schaeffer, R. W., \& Premack, D. Licking rates in infant albino rats. Science, 1961, 134, 1980-1981.

Stellar, E., \& Hill, J. H. The rat's rate of drinking as a function of water deprivation. Journal of Comparative and Physiological Psychology, 1952, 45, 96-102.

(Received for publication August 29, 1975.) 